\title{
Bioethanol Production from Waste Corn Using Saccharomyces cerevisiae and Aspergillus awamori
}

\author{
Ashish Kumar, L.P.S. Rajput, Sushma Nema and Keerti Tantwai* \\ Biotechnology Centre, Jawaharlal Nehru Krishi Vishwa Vidyalaya \\ Jabalpur-482004, MP, India \\ *Corresponding author
}

\section{Keywords \\ Bioethanol, solid state fermentation (SSF), \\ Simultaneous \\ Saccharification and fermentation \\ (SiSF), \\ Saccharomyces \\ cerevisiae, \\ Aspergillus \\ awamori \\ Article Info \\ Accepted: \\ 20 July 2019 \\ Available Online: \\ 10 August 2019}

\section{A B S T R A C T}

Bio-fuels have caught global attention in the last decade. They are renewable liquid fuels made from biological raw materials and have proved to be good substitutes for petroleum in the transportation sector. Being environment friendly, bio-fuels like ethanol and biodiesel can help us to conform to stricter emission norms. The present study was carried out with the objectives of analysing the major chemical constituents of waste corn collected from different locations, to optimize the fermentation variables for maximum yield of bioethanol using co-culture of Saccharomyces cerevisiae and Aspergillus awamori and evaluate the quality of bioethanol produced. The result analysed showed that the waste corn was found to contain good amount of carbohydrate source required for bioconversion into bioethanol. In this study for bioethanol production, main fermentation variables were optimized in solid state fermentation (SSF) and simultaneous Saccharification and fermentation (SiSF) methods using co-culture of Saccharomyces cerevisiae MTCC 170 and Aspergillus awamori MTCC 8840. The results of various experiments revealed that with the SSF technique, the highest yield of bioethanol (7.5\%) using co-culture of Saccharomyces cerevisiae MTCC 170 and Aspergillus awamori MTCC 8840 was obtained at incubation temperature of $30^{\circ} \mathrm{C}$ after $168 \mathrm{hr}$ of incubation period. In case of simultaneous Saccharification and fermentation (SiSF), the results of various experiments revealed that by employing co-culture of yeast and fungi the highest yield of bioethanol $(6.5 \%)$ was obtained at a $\mathrm{pH}$ of 6.0 with incubation temperature of $30^{\circ} \mathrm{C}$ after $168 \mathrm{hr}$ of incubation period. The results of various quality attributes of the bioethanol production showed that there were no major differences in values of density, viscosityof the bioethanol produced from both methods of fermentation.

\section{Introduction}

Bioethanol is the principal fuel used as a petrol substitute for road transport vehicles. The high price of crude oil makes biofuels attractive. Brazil has been a front runner in the use of renewable fuels. Currently the largest producers in the global biofuel industry are the united states and Brazil, where millions of tons of sugar are processed. Bioethanol fuel is mainly produced by the sugar fermentation process, although it can also be manufactured by the chemical process of reacting ethylene with steam. Domestic 
production and use of ethanol for fuel can decrease dependence on foreign oil, reduce trade deficits, create job in rural areas, reduce air pollution, global climate change and carbon dioxide build up. The drawbacks of bioethanol include its lower energy density than gasoline, its corrosiveness, low flame luminosity, lower vapour pressure (making cold starts difficult), miscibility with water and toxicity to ecosystems (Ibeto et al., 2011). Bioethanol can be obtained from a variety of feedstocks using cellulosic, starchy and sugar sources. These feedstocks include corn, sugar cane, sugarbeet, sorghum, switch grass, barley, hemp, potatoes, sunflower, wheat, wood, paper, straw, cotton and other biomass materials. Ethanol from corn is produced by the breakdown of complex starch molecules into the monosaccharide glucose, followed by fermentation of the glucose. Starch is the energy storage unit for plants that is made-up of polymers of glucose units. Starch is present in the endosperm, which is the major structure of corn and other cereal grains. Starch consists of two components, amylose and amylopectin. The starch must be broken down into individual glucose monomers to be fermented into ethanol by yeast. The ethanol produced by fermentation is then concentrated by distillation. Yeast species (Saccharomyces cerevisiae) are usually used for the ethanol fermentation because of its high production efficiency and stability to high glucose and alcohol concentrations (Butzen et al., 2003).

\section{Materials and Methods}

Bioethanol production from waste corn using Saccharomyces cerevisiae and Aspergillus awamori" was conducted in the Fermentation Technology Laboratory, Biotechnology Centre, Jawaharlal Nehru Krishi Vishwa Vidyalaya, Jabalpur (MP). Waste corn Kernels was purchased from different shops of Adhartal and krishi upaj mandi Jabalpur (MP). The bioethanol producing microorganisms i.e., co-culture viz., Saccharomyces cerevisiae MTCC 170 and Aspergillus awamori MTCC 8840 were obtained from Institute of Microbial Technology (IMTECH) Chandigarh, Punjab. The most important variable which is responsible for bioethanol production is the type of strain used in the bioconversion of starch into the desirable end products. The strain must have high yielding capacity and should not produce any undesirable substances. For the purpose of production of bioethanol, Saccharomyces cerevisiae MTCC 170 and Aspergillus awamori MTCC 8840 were selected and taken in the present investigation. In order to know the availability of corn, market survey of Jabalpur city in different locations were conducted to assess the stage of wastage to the corn. Based on it, corn at particular stage, not fit for human consumption, were selected in order to get higher yield and better quality of bioethanol. In this experiment, waste corn was taken as starch source (substrate) for bioethanol production using two different methods of fermentation namely solid-state fermentation (SSF) and simultaneous saccharification and fermentation (SiSF). Before processing, waste corn kernels were cleaned gently with potable water thoroughly and washed corn kernels were boiled in distilled water containing $0.5 \%$ potassium metabisulphite for 30 minutes. Boiled corn kernels were mashed and dried at $70^{\circ} \mathrm{C}$ for about 7 hours in a hot air oven. After drying, it was ground to fine powder and sieved to remove big particles. The culture of Saccharomyces cerevisiae and Aspergillus awamori were grown and maintained on Yeast Extract Peptone Dextrose and Malt Extract Agar media respectively. The culture of Saccharomyces cerevisiae and Aspergillus awamori were maintained by sub culturing them every 15 days on YEPD and MEA agar plates, incubating for $24 \mathrm{hrs}$ and 7 days respectively at $30^{\circ} \mathrm{C}$ and thereafter storing in a refrigerator at $4^{\circ} \mathrm{C}$ until further 
use.Inoculum of Saccharomyces cerevisiae and Aspergillus awamori was prepared separately in YEPD and malt extract broth. A loopful of 24 and 7 days old culture of Saccharomyces cerevisiae and Aspergillus awamori was inoculated and incubated at $30^{\circ} \mathrm{C}$ on a rotary shaker at $200 \mathrm{rpm}$ for 24 hours. These inoculums were used to inoculate sterilized corn samples. Two different fermentation methods were used for production of bioethanol from waste corn by employing solid state fermentation (Rani et al., 2010) and simultaneous saccharification and fermentation (Rath et al., 2014) using coculture of $S$. cerevisiae and A. awamori. For solid state fermentation (SSF) and simultaneous saccharification and fermentation (SiSF) method, different variables viz. temperature, $\mathrm{pH}$ and incubation periods were studied for better recovery of bioethanol. In SSF method, maintaining the optimum condition of moisture content at $60 \%$ level, production of bioethanol was carried out at different incubation temperatures viz. $28, \quad 30$ and $32^{\circ} \mathrm{C}$ for different incubation periods viz. 120, 144, 168 and 192 hours in order to attain for maximum recovery of bioethanol using co-culture of $S$. cerevisiae MTCC 170 and A. awamori MTCC 8840. Similar to solid state fermentation method, simultaneous saccharification and fermentation method was also used for carrying out the experiments on optimization of different fermentation variables $(\mathrm{pH}$, incubation temperature and incubation period) in order to get maximum yield of bioethanol. The process of fermentation was carried out at different temperatures viz. 28, 30 and $32^{\circ} \mathrm{C}$ for different incubation periods viz. 120,144, 168 and 192 days with different ranges of $\mathrm{pH}$ viz. 5.5, 6.0, 6.5 and $7.0 \mathrm{pH}$ for maximum recovery of bioethanol using co-culture of $S$. cerevisiae MTCC 170 and A. awamori MTCC 8840 . The yield of bioethanol was determined by distillation and dehydration process adopted by O'Leary (2000). Distillation and dehydration were done using rotary evaporator at $78 \pm 2^{\circ} \mathrm{C}$ under vacuum. Waste corn was analysed for various chemicalconstituents like moisture, dry matter content, amylase and amylopectin contents according to AOAC (1980). Total starch content (Keer, 1950) was also recorded. Quality of bioethanol produced was assessed using two different parameters like density determination using pycnometer (Caylak and Sukan 1998), viscosity by Ostwald Viscometer (Bernnan and Tipper, 1967).

\section{Results and Discussion}

The observations recorded revealed that waste corn contained moisture $11.50 \%$, dry matter $88.50 \%$, starch $70.5 \%$, amylose $26.3 \%$ and amylopectin $44.2 \%$ (Table 1). Chemical composition of waste corn revealed that various chemical constituents viz. moisture, dry matter, starch, amylose and amylopectin were having the similar composition as reported in the literature, although some variations in the values were observed (Wang et al., 2007, Nikolic et al., 2008, Kumar et al., 2018). In this investigation, the minor difference in the values of various chemical constituents observed in the substrate (corn) might be due to the genetic variability and purity of the materials taken by various workers in earlier studies. In addition to these, environmental conditions and other factors might have also played some role in influencing the composition of various constituents. In this investigation, various experiments were conducted on waste corn using both the method of fermentation i.e. Solid State Fermentation (SSF) and Simultaneous Saccharification and Fermentation (SiSF) at different temperatures, $\mathrm{pH}$ and incubation periods for obtaining the maximum yield of bioethanol. In SSF method, maximum bioethanol concentration $7.5 \%$ was obtained at incubation period of $168 \mathrm{hr}$ having maintained optimum incubation 
temperature of $30^{\circ} \mathrm{C}$ from co-culture of $S$. cerevisiae MTCC 170 and A. awamori MTCC 8840 (Table 2). The value of bioethanol yield was found minimum and recorded as $5.7 \%$ from the co-culture of $S$. cerevisiae MTCC 170 and $A$. awamori MTCC 8840 at incubation temperature of $32^{\circ} \mathrm{C}$ and incubation period of $192 \mathrm{hr}$. It was interesting to note that with the advancement in incubation period from 120 to $168 \mathrm{hr}$, there was a relative increase in bioethanol yield and thereafter it got reduced at incubation period of $192 \mathrm{hr}$ using co-culture of yeast and fungi (Fig. 1). Various workers have also reported the similar pattern of bioethanol yield using yeast and fungi (Manikandan and Viruthagiri, 2010; Rani et al., 2010; Swain et al., 2013). Manikandan and Viruthagiri (2010) reported the maximum ethanol yield of $63.04 \mathrm{~g} / \mathrm{l}$ at the optimum temperature of $30^{\circ} \mathrm{C}$ from SSF using corn flour. Rani et al., (2010) also observed $59.9 \mathrm{~g} / \mathrm{l}$ bioethanol obtained at $30^{\circ} \mathrm{C}$ temperature after $48 \mathrm{hr}$ incubation periods from Potato flour using yeast. Swain et al., (2013) reported the optimization of coculturing of Trichoderma sp. and S. cerevisiae (1:4 ratio) on sweet potato (Ipomoea batatas L.) flour (SPF) for the production of bioethanol in solid state fermentation (SSF). Maximum bioethanol (172 $\mathrm{g} / \mathrm{kg}$ substrate) was produced in a medium containing $80 \%$ moisture, ammonium sulphate $0.2 \%, \mathrm{pH} 5.0$, inoculated with $10 \%$ inoculum size and fermented at $30^{\circ} \mathrm{C}$ for $72 \mathrm{hr}$. In the present investigation, it was observed that the bioconversion efficiency of starch into bioethanol was greater due to optimum growth, metabolism and survival of the fermenting organism. Hence it was concluded that fermentation at $30^{\circ} \mathrm{C}$ temperature with $168 \mathrm{hr}$ incubation period was found optimum for maximum bioethanol production under solid state condition with co-culture of $S$. cerevisiae MTCC 170 and A. awamori MTCC 8840. In SiSF method, the observation indicated that the co-culture of $S$. cerevisiae
MTCC 170 and A. awamori MTCC 8840 gave maximum yield of bioethanol $(6.5 \%)$ at an incubation temperature of $30^{\circ} \mathrm{C}$ with incubation period of $168 \mathrm{hr}$ and having maintained the $\mathrm{pH}$ at 6.0. It is presumed that the rate of fermentation typically increased at $30^{\circ} \mathrm{C}$ with increase in incubation period up to $168 \mathrm{hr}$. However, the bioethanol yields further got decreased at an incubation period of 192 hr (Table 3-6). It is also presumed that when the temperature and incubation period increase after the optimum condition, the percentage of bioethanol might also decrease as the enzymes begin to denature and unfold and thus become inactive (Fig. 2). Several workers have also reported the bioethanol yield almost in the similar range from bioconversion of starch rich substrates using yeast and fungi (Buruiana et al., 2014; Kim et al., 2015; Katsimpouras et al., 2018). Buruiana et al., (2014) reported the production of bioethanol by autohydrolysis and further Simultaneous Saccharification and Fermentation (SSF) of pretreated solids. The glucan conversion into ethanol reached values up to $86 \%$, with a bioethanol concentration of $37.8 \mathrm{~g} / \mathrm{L}$. Fed-batch operation in the SSF stage allowed the utilization of higher solid loadings, allowing an increase in the bioethanol concentration up to $51.6 \mathrm{~g} / \mathrm{L}$. Kim et al., 2015 explored the application of glucose and xylose from corn stover pretreated with nitric acid $\left(\mathrm{HNO}_{3}\right)$ for the co-production of bioethanol and biodiesel. The optimal reaction condition was $151.9^{\circ} \mathrm{C}$, $0.68 \% \mathrm{HNO}_{3}$ and $2.5 \mathrm{~min}$, which resulted in the highest xylose yield of $77.8 \%$ and glucan content of $57.1 \%$. Quasi-simultaneous saccharification and fermentation (Q-SSF) of pretreated corn stover with $S$. cerevisiae gave an ethanol concentration of $22.4 \mathrm{~g} / \mathrm{L}$, corresponding to $69.1 \%$ theoretical ethanol yield based on initial cellulose weight. Katsimpouras et al., (2018) investigated that ethanol production to achieve concentrations over the threshold for an economical 
distillation process and concurrently reduced water consumption. It was reported that the combination of an acetone/water oxidation pretreatment process (AWO) with a liquefaction/ saccharification step, used a free-fall mixer, before simultaneous saccharification and fermentation (SSF) could increase ethanol concentrations up to $74 \mathrm{~g} / 1$ at solids content of $20 \%$ by weight. The density of bioethanol produced by SSF method was $1.0644 \pm 0.163 \mathrm{~g} / \mathrm{ml}$ whereas it was recorded as $1.0420 \pm 0.017 \mathrm{~g} / \mathrm{ml}$ for bioethanol produced by SiSF method. Some reports have also been published in the literature on density of bioethanol under varied fermentation conditions (Caylak and Sukan 1996; Meenakshi and Kumaresan 2014; Patil 2014). Caylak and Sukan (1996) reported the final ethanol concentration of $96.71 \mathrm{~g} / \mathrm{L}$ equivalent to $0.9818 \mathrm{~g} / \mathrm{ml}$ density of bioethanol. The findings in present investigation are in agreement with the reported observations by earlier workers. Patil (2014) reported that the values of density of bioethanol produced by SSF and SiSF methods using the co-culture of
S. cerevisiae MTCC 170 and Zymomonas mobilis MTCC 2427 were $1.0218 \mathrm{~g} / \mathrm{ml}$ and $1.0245 \mathrm{~g} / \mathrm{ml}$ respectively. The observations showed that the viscosity value of bioethanol produced by SSF method using the co-culture of $S$. cerevisiae MTCC 170 and A. awamori MTCC 8840 was recorded as $0.97 \pm 0.050$ centipoise whereas it was recorded as $0.98 \pm 0.058$ centipoise for the bioethanol produced from the same co-culture using SiSF method. Several workers have also reported the viscosity of bioethanol under varied fermentation conditions (Ghobadian et al., 2008; Rai et al., 2013; Meenakshi and Kumaresan 2014). Ghobadian et al., (2008) studied the production of bioethanol and sunflower methyl ester and investigated fuel blend properties and reported the viscosity of ethanol as 1.10 centipoise. Rai et al., (2013) also observed that viscosity of bioethanol was found 1.02 and 1.07 centipoise at SSF and SiSF method respectively. The values of viscosity of bioethanol in the present investigation also indicated the similar pattern as reported by earlier worker

Table.1 Chemical composition of waste corn for suitability in the production of bioethanol

\begin{tabular}{|c|l|c|}
\hline S. No. & \multicolumn{1}{|c|}{ Constituents } & Amount (\%) \\
\hline 1. & Moisture & $11.50 \pm 2.03$ \\
\hline 2. & Dry matter (on dry weight basis) & $88.50 \pm 1.22$ \\
\hline 3. & Starch & $70.5 \pm 4.16$ \\
\hline 4. & Amylose & $26.3 \pm 2.45$ \\
\hline 5. & Amylopectin & $44.2 \pm 0.98$ \\
\hline
\end{tabular}

Table.2 Effect of incubation temperature on bioethanol yield at different incubation period in SSF method. Substrate taken - 80 gm, Water added $-20 \mathrm{ml}$

\begin{tabular}{|c|c|c|c|c|}
\hline \multirow{2}{*}{ S.No. } & Incubation period & \multicolumn{3}{|c|}{ Yield of bioethanol (\%) } \\
\cline { 3 - 5 } & & \multicolumn{3}{|c|}{ Temperature $\left({ }^{\circ} \mathrm{C}\right)$} \\
\hline & & 28 & 30 & 32 \\
\hline $\mathbf{1 .}$ & 120 & $6.7 \pm 0.249$ & $6.5 \pm 0.125$ & $6.2 \pm 0.163$ \\
\hline $\mathbf{2 .}$ & 144 & $7.0 \pm 0.163$ & $6.9 \pm 0.141$ & $6.8 \pm 0.163$ \\
\hline $\mathbf{3 .}$ & 168 & $7.4 \pm 0.294$ & $7.5 \pm 0.205$ & $7.4 \pm 0.205$ \\
\hline $\mathbf{4 .}$ & 192 & $7.2 \pm 0.898$ & $7.3 \pm 0.163$ & $5.7 \pm 0.205$ \\
\hline
\end{tabular}


Table.3 Effect of pH 5.5 on yield of bioethanol in SiSF method at different incubation temperatures and incubation periods. Substrate taken $-5 \mathrm{gm}$, Water added $-96 \mathrm{ml}$

\begin{tabular}{|c|c|c|c|c|}
\hline \multirow{2}{*}{ S.No. } & Incubation period & \multicolumn{3}{|c|}{ Yield of bioethanol (\%) } \\
\cline { 3 - 5 } & (hr) & \multicolumn{3}{|c|}{ Temperature $\left({ }^{\circ} \mathrm{C}\right)$} \\
\cline { 3 - 5 } & & 28 & 30 & 32 \\
\hline $\mathbf{1 .}$ & 120 & $3.5 \pm 0.081$ & $3.9 \pm 0.685$ & $3.2 \pm 0.283$ \\
\hline $\mathbf{2 .}$ & 144 & $3.6 \pm 0.123$ & $4.5 \pm 0.172$ & $3.7 \pm 0.145$ \\
\hline 3. & 168 & $3.8 \pm 0.094$ & $4.7 \pm 0.303$ & $4.0 \pm 0.568$ \\
\hline $\mathbf{4 .}$ & 192 & $3.7 \pm 0.029$ & $4.5 \pm 0.163$ & $3.9 \pm 0.160$ \\
\hline
\end{tabular}

Table.4 Effect of pH 6.0 on yield of bioethanol in SiSF at different incubation temperatures and incubation periods. Substrate taken $-5 \mathrm{gm}$, Water added $-96 \mathrm{ml}$

\begin{tabular}{|c|c|c|c|c|}
\hline \multirow{2}{*}{ S.No. } & \multirow{2}{*}{ Incubation period (hr) } & \multicolumn{3}{|c|}{ Yield of bioethanol (\%) } \\
\cline { 3 - 5 } & & \multicolumn{3}{|c|}{ Temperature $\left({ }^{\circ} \mathrm{C}\right)$} \\
\cline { 3 - 5 } & & 28 & 30 & 32 \\
\hline $\mathbf{1 .}$ & 120 & $4.4 \pm 0.077$ & $5.5 \pm 0.160$ & $4.8 \pm 0.085$ \\
\hline $\mathbf{2 .}$ & 144 & $4.6 \pm 0.171$ & $6.2 \pm 0.408$ & $5.0 \pm 0.229$ \\
\hline $\mathbf{3 .}$ & 168 & $4.8 \pm 0.257$ & $6.5 \pm 0.173$ & $5.4 \pm 0.148$ \\
\hline $\mathbf{4 .}$ & 192 & $4.5 \pm 0.063$ & $6.4 \pm 0.180$ & $5.1 \pm 0.064$ \\
\hline
\end{tabular}

Table.5 Effect of pH 6.5 on yield of bioethanol in Simultaneous Saccharification and Fermentation (SiSF) at a different incubation temperatures and incubation periods. Substrate taken $-5 \mathrm{gm}$, Water added $-96 \mathrm{ml}$

\begin{tabular}{|c|c|c|c|c|}
\hline \multirow{2}{*}{ S.No. } & Incubation & \multicolumn{3}{|c|}{ Yield of bioethanol (\%) } \\
\cline { 3 - 5 } & \multirow{2}{*}{$\begin{array}{c}\text { period } \\
\text { (hr) }\end{array}$} & \multicolumn{3}{|c|}{ Temperature $\left({ }^{\circ} \mathbf{C}\right)$} \\
\cline { 3 - 5 } & & 28 & 30 & 32 \\
\hline 1. & 120 & $3.8 \pm 0.137$ & $4.1 \pm 0.258$ & $3.6 \pm 0.290$ \\
\hline 2. & 144 & $4.5 \pm 0.318$ & $4.6 \pm 0.155$ & $4.2 \pm 0.170$ \\
\hline 3. & 168 & $5.3 \pm 0.245$ & $5.3 \pm 0.236$ & $4.8 \pm 0.408$ \\
\hline 4. & 192 & $4.7 \pm 0.331$ & $5.0 \pm 0.311$ & $4.4 \pm 0.245$ \\
\hline
\end{tabular}

Table.6 Effect of pH 7.0 on yield of bioethanol in SiSF at different incubation temperatures and incubation periods. Substrate taken $-5 \mathrm{gm}$, Water added $-96 \mathrm{ml}$

\begin{tabular}{|c|c|c|c|c|}
\hline S.No. & Incubation & \multicolumn{3}{|c|}{ Yield of bioethanol (\%) } \\
\cline { 3 - 5 } & period & \multicolumn{3}{|c|}{ Temperature $\left({ }^{\circ} \mathbf{C}\right)$} \\
\cline { 3 - 5 } & (hr) & 28 & 30 & 32 \\
\hline 1. & 120 & $4.2 \pm 0.159$ & $4.5 \pm 0.057$ & $3.5 \pm 0.155$ \\
\hline 2. & 144 & $4.6 \pm 0.326$ & $5.1 \pm 0.245$ & $4.2 \pm 0.170$ \\
\hline 3. & 168 & $5.5 \pm 0.653$ & $5.7 \pm 0.412$ & $4.4 \pm 0.249$ \\
\hline 4. & 192 & $5.0 \pm 0.408$ & $5.3 \pm 0.401$ & $4.3 \pm 0.086$ \\
\hline
\end{tabular}

$*$ Values presented are average of triplicates \pm Standard deviation 
Fig.1 Effect of incubation temperature on bioethanol yield at different incubation period in SSF method. Substrate taken $-20 \mathrm{~g}$, Water added - $80 \mathrm{ml}$

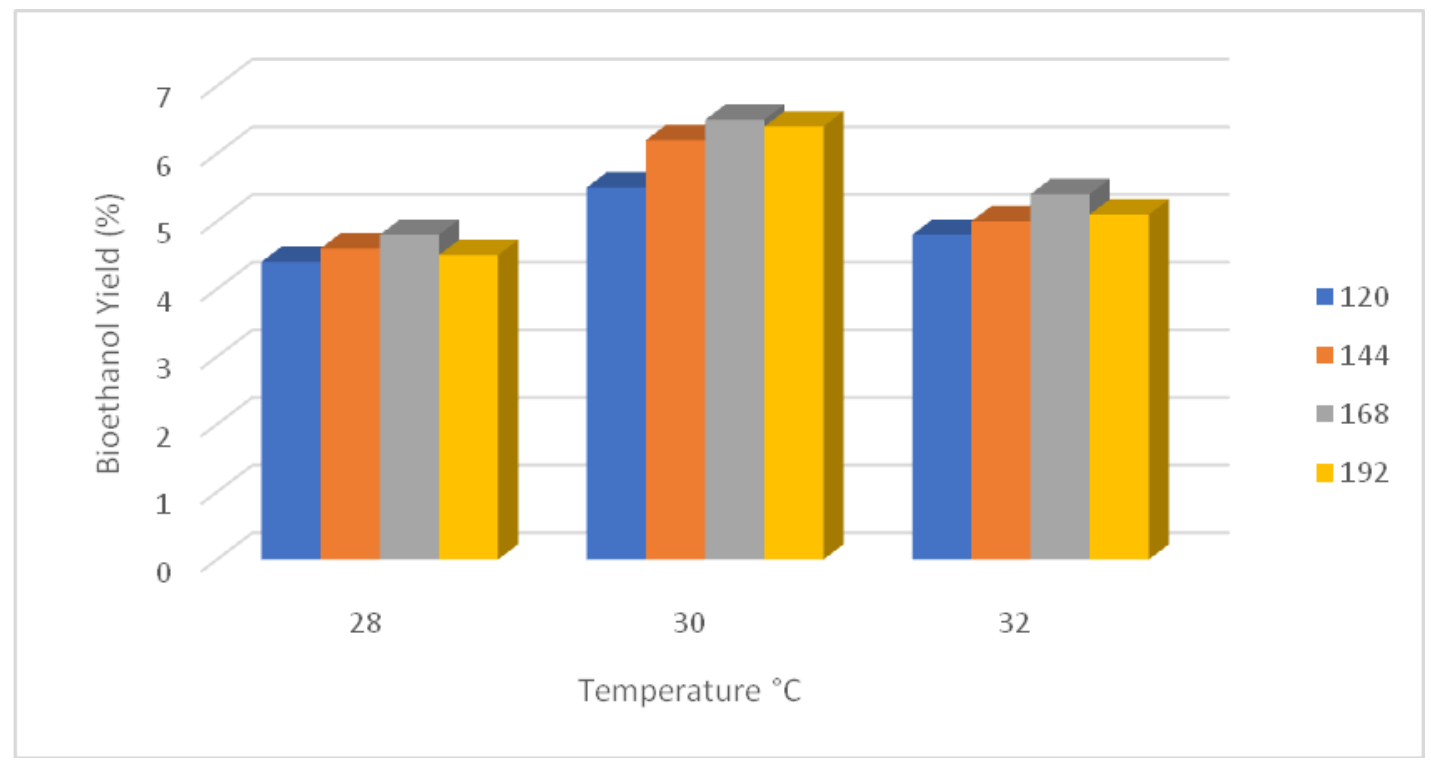

Fig.2 Effect of pH 6.0 on yield of bioethanol in SiSF at different incubation temperatures and incubation periods. Substrate taken - 5 g, Water added - $96 \mathrm{ml}$

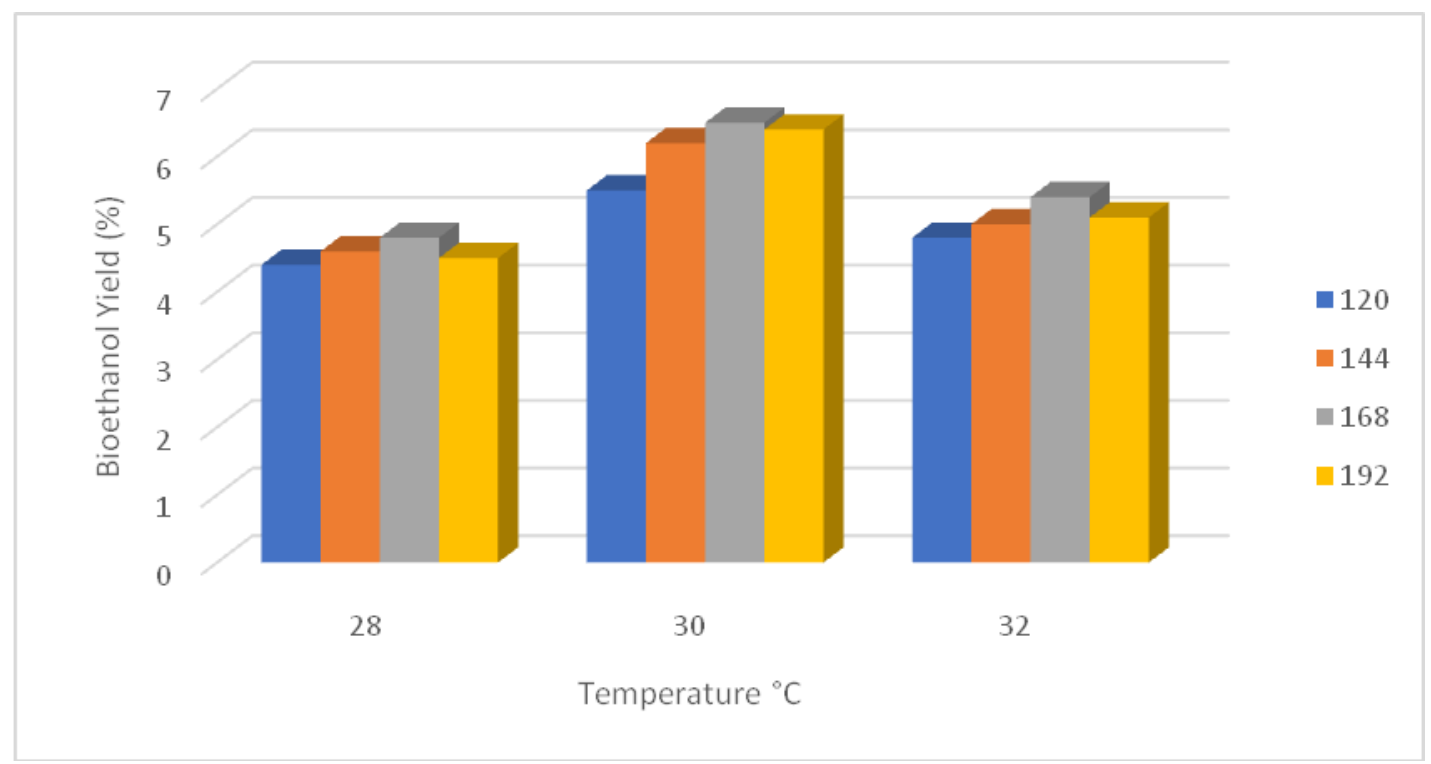

In conclusion the major chemical constituents showed that the waste corn contained a good amount of starch and could be used as substrate for bioconversion into bioethanol. Using the method of solid state fermentation (SSF), highest yield $(7.5 \%)$ was obtained at incubation temperature of $30^{\circ} \mathrm{C}$ after incubation period of $168 \mathrm{hr}$ and in SiSF method, highest yield $(6.5 \%)$ of bioethanol was obtained using co-culture of Saccharomyces cerevisiae MTCC 170 and Aspergillus awamori MTCC 8840 at incubation temperature of $30^{\circ} \mathrm{C}$ after incubation period of $168 \mathrm{hr}$ at $\mathrm{pH}$ of 6.0. 


\section{Acknowledgements}

Special thanks go to the Biotechnology centre for the support given to achieve this research work.

\section{References}

AOAC. 1980. Official method of analysis, 23 Ed., Association of Official Analytical Chemists, Washington, DC.

Brennan D and Tipper CFH. 1967. A laboratory manual of experiments in physical chemistry, Graw- Hill publishing company 19.

Buruiana CT, Vizireanu C, Garrote $\mathrm{G}$ and Parajó JC. 2014. Optimization of corn stover biorefinery for coproduction of oligomers and second generation bioethanol using non-isothermal autohydrolysis.Industrial Crops and Products54: 32-39.

Butzen S, Haefele D and Hillard P. (2003). Corn processing II: Dry-grind ethanol production. Crop Insights. 13(3): 1-4.

Caylak B and Sukan FV. 1998. Comparison of different production process for bioethanol. Turkish Journal of Chemistry. 22: 351-359.

Ghobadian B, Rahimi H, Hashjin TT and Khatamifar M. 2008. Production of bioethanol and sunflower methyl ester and investigation of fuel blend properties. Journal of Agriculture Science and Technology 10: 225-232.

Ibeto CN, Ofoefule AU and Agbo KE.2011. A Global Overview of Biomass Potentials for Bioethanol Production: A Renewable Alternative Fuel. Trends in Applied Sciences Research 6(5): 410425.

Katsimpouras C, Dedes G, Bistis P, Kekos D, Kalogiannis KG and Topakas E. 2018. Acetone/water oxidation of corn stover for the production of bioethanol and prebiotic oligosaccharides.Bioresource
Technology 270: 208-215.

Keer RW. 1950. Chemistry and industry of starch. Academic press, Inc New York. 659-672.

Kumar D, Juneja A and Singh V. 2018.Fermentation technology to improve productivity in dry grind corn process for bioethanol production. Fuel Processing Technology. 173: 66-74.

Kim I, Seo YH, Kim G and Han J. 2015. Coproduction of bioethanol and biodiesel from corn stover pretreated with nitric acid. Fuel143: 285-289.

Manikandan K and Viruthagiri T. 2010. Kinetic and optimization studies on ethanol production from corn flour. World Academy of Science, Engineering and Technology 4: 01-24.

Meenakshi A and Kumaresan R. 2014. Ethanol production from corn, potato peel waste and its process development. International Journal of Chemtech Research 6(5): 2843-2853.

Nikolic S, Mojovic L, Rakin M, Pejin D and Savic D. 2008. A microwave-assisted liquification as a pretreatment for the bioethanol production by the simultaneous saccharification and fermentation of corn meal. Chemical Industry \& Chemical Engineering Quarterly 14(4): 231-234.

O, Leary D. 2000. Ethanol online: available on http:// www. Ethanol. Org

Patil YS. 2014. Bioethanol production from waste potato using co-culture of Saccharomyces cerevisiae and Zymomonas mobilis. M.Sc. Thesis, JNKVV, Jabalpur. 47p.

Rai SK, Rajput LPS, Singh Y and Tantwai K. 2013. Bioethanol production from waste potatoes using bacterium Zymomonas mobilis MTCC 2427. Applied Biological Research 15(2): 154-158.

Rani P, Sharma S, Garg FC, Raj K and Wati L. 2010. Ethanol production from potato flour by Saccharomyces 
cerevisiae. Indian Journal of Science and Technology 3(7): 733-736.

Rath S, Singh AK, Masih H, Kumar Y, Peter JK, Singh P and Mishra SK. 2014. Bioethanol production from waste potato as an environmental waste management and sustainable energy by using co cultures Aspergillus niger and Saccharomyces cerevisiae. International Journal of Advanced Research 2(4): 553-563.

Swain MR, Mishra J and Thatoi H. 2013. Bioethanol production from sweet potato (Ipomoea batatas L.) flour using co-culture of Trichoderma sp. And Saccharomyces cerevisiae in solid-state fermentation. Brazilian Archives of Biology and Technology 56(2): 171179.

Wang P, Singh V, Xue H, Johnston DB, Rausch KD and Tumbleson ME. 2007. Comparison of raw starch hydrolyzing enzyme with conventional liquefaction and saccharification enzymes in drygrind corn processing. Cereal Chemistry 84(1): 10-14.

\section{How to cite this article:}

Ashish Kumar, L.P.S. Rajput, Sushma Nema and Keerti Tantwai. 2019. Bioethanol Production from Waste Corn Using Saccharomyces cerevisiae and Aspergillus awamori. Int.J.Curr.Microbiol.App.Sci. 8(08): 2437-2445. doi: https://doi.org/10.20546/ijcmas.2019.808.283 